\title{
TWO SIBLINGS WITH FULMINANT VIRAL HEPATITIS A: CASE REPORT
}

\author{
Mehmet Yalniz ${ }^{1}$, Hüseyin Ataseven ${ }^{1}$, Selman Çelebı ${ }^{1}$, Orhan Kürşat Poyrazoğlu ${ }^{1}$, Nusret Sirma ${ }^{2}$, \\ Ibrahim Halil Bahçecıoğlu ${ }^{1}$
}

Firat University, Faculty of Medicine, Turkey: Department of Gastroenterology ${ }^{1}$, Department of Internal Medicine ${ }^{2}$

\begin{abstract}
Summary: Fulminant hepatitis is a rare complication of acute hepatitis A infection. Nevertheless, the seroepidemiology of the infection is rapidly changing with the developing world, rendering more adults susceptible to the infection, in particular with more severe course. We report here fulminant hepatitis A infection with a mortal course during an epidemic period in two siblings. Although it causes a self-limited mild disease, hepatitis A virus may have a severe course including fulminant hepatitis and may lead to mortality, especially in older ages. Hence, the risk of hepatitis A virus infection and its complications should be reduced with measures of immunization and sanitation.
\end{abstract}

Key words: Fulminant hepatitis; Viral hepatitis A; Sibling

\section{Introduction}

Hepatitis A virus (HAV) is the most common cause of viral hepatitis. It usually leads to a self-limited, mild hepatitis. However, it can also rarely cause fulminant hepatitis both in children and in adults.

The etiologic factors vary in different geographic regions; however, the most common causes are hepatitis viruses $(3,10,13,15,16,19)$. Considering the hepatitis viruses, hepatitis $\mathrm{B}$ virus is the most common etiologic factor followed by hepatitis A virus.

Fulminant hepatitis (FH), complicates $0.14-2 \%$ of the HAV infections (9). Nonetheless, the rate of FH during the course of the hepatitis A infection may increase with the presence of underlying disease like chronic hepatitis $\mathrm{B}$ and $\mathrm{C}$ infections $(14,17)$. Other factors that predisposes for the development of FH in HAV infection are advanced age and addiction of intravenous drugs $(1,8)$.

Although several familial FH cases due to hepatitis $\mathrm{B}$ have been reported, only one case report of $\mathrm{FH}$ within the same family due to HAV infection has been reported in the literature (7). We report here two siblings with FH due to HAV which has been seen extremely rare.

\section{Cases}

Smallest brother of the cases had a non-fulminant acute hepatitis with malaise, fatigue and icterus symptoms lasting 15 days during a school endemic of viral hepatitis A. Labo- ratory analyzing revealed a HAV Ig M positivity. None of the cases during the endemic hepatitis A had developed a fulminant course.

Case 1: One week after recovery of the aforementioned case, the older, 16 years old, brother had fatigue, nausea and vomiting symptoms. He referred to hospital because of the development of jaundice. The patient hospitalized with diagnosis of acute hepatitis had a progressive course and encephalopathy developed four days after the onset of the clinical symptoms. Physical examination and laboratory analysis revealed features specific to fulminant hepatitis including flapping tremor, icterus at the sclera and bilirubinuria $(++++)$. Prothrombin time (PT) was very high (over the values that could be analyzed) and cannot be determined. Other liver function tests were as follows: Aspartat aminotrasferase (AST): $2800 \mathrm{U} / \mathrm{L}$, Alanine aminotransferase (ALT): $4080 \mathrm{U} / \mathrm{L}$, Gama glutamyl transpeptidase (GGT): 80 U/L, Alkaline phosphatase (ALP): $290 \mathrm{U} / \mathrm{L}$, total bilirubin: 73.8 and $75.15 \mathrm{gr} / \mathrm{dl}$, direct bilirubin: $30 / 29.4 \mathrm{gr} / \mathrm{dl}$. Blood sugar level was very low, $36 \mathrm{mg} / \mathrm{dl}$. Blood urea and creatinine values showed a progressive increase although initial values were normal. Complete blood count, electrolytes, total protein and albumin levels were normal. HAV Ig M was positive while other serologic markers specific to hepatitis were negative. Supportive treatment of FH did not alleviate the worse course of the clinical condition and the patient died prior to referring to a transplantion center for liver transplantation.

Case 2: Two weeks later, 18 years old sister of the two siblings applied to the gastroenterology clinic with similar 
clinical findings. She had a normal physical examination except icterus at skin and sclera. Bilirubin was positive in the urine analysis. In addition, liver function tests were abnormal as follows: AST: $4750 \mathrm{IU} / \mathrm{L}$, ALT: $5062 \mathrm{IU} / \mathrm{L}$, total bilirubin: $23.45 \mathrm{gr} / \mathrm{dl}$, direct bilirubin: $16.84 \mathrm{gr} / \mathrm{dl}$, PT was 20.1 second. These abnormal levels decreased gradually towards normal except a temporarily increase in bilirubine values. Serologic markers except HAV IgM were negative. Second day of hospitalization, hepatic encephalopathy developed and the patient lost her consciousness. Fortunately, she recovered with the treatment of encephalopathy and was discharged from the hospital without any complication.

\section{Discussion}

HAV usually causes subclinical infection during the childhood. Nonetheless, it can also cause acute liver failure and death both in childhood and adults. Fulminant hepatitis is a rare complication of HAV. Moreover, it has not been frequently seen between siblings and there is only one report in the literature (7).

HAV contaminates via fecal-oral route and spreads in crowded and unhealthy conditions. It is also easily transmitted among the individuals in the school or family $(2,5)$. Two important transmission ways, intra-school and intrafamily, had role on the spreading of the HAV and serve as the source of the infection for cases of the present study.

The mechanisms responsible for the development of acute liver failure and subsequent $\mathrm{FH}$ in some patients infected with HAV are not clear. However, host factors, virulence and amount of transmitted virus load are claimed to be effective in the pathogenesis. Genetic predisposition has also been claimed to play a role in the severe course of the HAV; however, it is not well established (4).

Underlying liver disease and age are the most accused host factors $(1,14,17)$. Morbidity and the risk of development of FH proportionally increase with age (4). The rate of mortality remarkably increases in patients especially over the age of 40 years (18). Either cases reported here did not have any underlying hepatic or non-hepatic diseases and all serologic markers specific to hepatitis were also negative. Although the age of our cases was not very advanced, they were older than the typical presentation time of HAV infection. It appears that age is an important factor responsible from the severe course of the disease and it is of note that the older case presented in this report had a more severe and fatal course. A possible role of genetic predisposition of the host (6) might also be considered an important factor responsible for the severe course because of being brother of the cases, however, it is difficult to prove this.

It may also be supposed that pathogenicity of some strains of HAV is stronger. However, Fujiwara et al. (11), recently reported that genotype of HAV is not the main factor that determine the severity of disease during HAV infection. As a matter of fact, non-fulminant course of the endemic HAV infection at the school, source of the infection, supports the point of view that genotype does not take role upon the severity of the disease. In view of these circumstances, it appears that host factors are main factors affecting the course of the infection. As well, a genetic predisposition might also be considered responsible for the severity.

FH due to HAV may improve spontaneously. Liver transplantation may be performed, however, long-term survival is relatively poor compared to other indications of liver transplantation (12). Hence, decision of transplantation in $\mathrm{FH}$ due to HAV is difficult. First, treatment is directed to complications, and liver transplantation might be considered according to the possibility of the center, the patient is followed.

The existent clinical findings and the complications developed were treated. The case that died could not referred to a transplantation center due to aggressive course

In brief, seroepidemiology of HAV infection, which generally causes disease during childhood, is changing with the developing world. The infection is getting more encountered at the adulthood with a more severe course. Thus, HAV infection, a preventable disease, and its complications should be diminished with immunization and general sanitation measures.

\section{References}

1. Akriviadis EA, Redeker AG. Fulminant hepatitis A in intravenous drug users with chronic liver disease. Ann Intern Med 1989;10(10):838-9.

2. Arguedas MD, Fallon MB. Hepatitis A Curr Treat Options Gastroenterol 2004;7(6):443-50

3. Arora NK, Mathur P, Ahuja A, Oberoi A. Acute liver failure. Indian J Pediatr 2003;70(1):73-9

4. Brown GR, Persley K. Hepatitis A epidemic in the elderly. South Med J 2002;95:826-33.

5. Cobden I, James OF. A biphasic illness associated with acute hepatitis A virus infection. J Hepatol 1986;2(1):19-23.

6. Debray D, Cullufi P, Devictor D, Fabre M, Bernard O. Liver failure in children with hepatitis A. Hepatology 1997;26(4):1018-22.

7. Durst RY, Goldsmidt N, Namestnick J, Safadi R, Ilan Y. Familial cluster of fulminant hepatitis A infection. J Clin Gastroenterol 2001;32(5):453-4.

8. Fagan E, Yousef G, Brahm J et al. Persistence of hepatitis A virus in fulminant hepatitis and after liver transplantation. J Med Virol 1990;30:131-6.

9. Fagan EA, Williams R. Fulminant viral hepatitis. Br Med Bull 1990;46:462-80.

10. Fingerote RJ, Bain VG. Fulminant hepatic failure. Am J Gastroenterol 1993; 88:1000-10.

11. Fujiwara K, Yokosuka O, Fukai K, Imazeki F, Saisho H, Omata M. Analysis of full-length hepatitis A virus genome in sera from patients with fulminant and selflimited acute type A hepatitis. J Hepatol 2001;35:112-9.

12. Hoofnagle JH, Carithes RL, Shapiro C, Ascher N. Fulminant hepatic failure: summary of a workshop. Hepatology 1995;21:240-1.

13. Hughens RD, Wendon J, Gimson AES. Acute liver failure. Gut 1991; (suppl) $86-91$.

14. Keeffe EB. Is hepatitis A more severe in patients with chronic hepatitis B and other chronic liver disease? Am J Gastroenterol 1995;90(2):201-95.

15. Lee WM. Acute liver failure. New Eng J Med 1993;329:1862-72.

16. Mc Neill M, Hoy JF, Richards MJ. Etiology of fatal hepatitis in Melbourne. Med J Aust 1984;141:637-40.

17. Vento S, Garofano T, Renzini C et al. Fulminant hepatitis associated with hepatitis A virus superinfection in patients with chronic hepatitis C. N Engl J Med 1998;338(5):286-90.

18. Willner IR, Uhl MD, Howard SC, Williams EQ, Riely Ca, Waters B. Serious Hepatitis A: an analysis of patients hospitalized during an urban epidemic in the United States. Ann Inter Med 1998;128:111-4. 
19. Yee HF, Lidofsky SD. Fulminant hepatic failure. In: Feldman M, Scharschmidt BF, Sleisenger MH:Eds. Gastrointestinal and liver disease. London WB Saunders Company, 1988:1355-64.

Submitted May 2005.

Accepted August 2005.

Mehmet Yalniz,

Furat Üniversitesi Gastroenteroloji BD,

23100 Elazığ,

Turkey.

E-mail: mehmetyalniz@hotmail.com 